\title{
Relation of alpha-1-antitrypsin phenotype to the performance of pulmonary function tests and to the prevalence of respiratory illness in a working population
}

\author{
R. B. C OLE, N.C. NEVIN, G. B L U N D ELL, \\ J. D. MER RET T, J.R. M C D O N A D, \\ and W. P. JOH N T O N \\ Departments of Medicine and Medical Statistics, Queen's University of Belfast, \\ and Department of Clinical Chemistry, Belfast City Hospital
}

\begin{abstract}
Cole, R. B., Nevin, N. C., Blundell, G., Merrett, J. D., McDonald, J. R., and Johnston, W. P. (1976). Thorax, 31, 149-157. Relation of alpha-1-antitrypsin phenotype to the performance of pulmonary function tests and to the prevalence of respiratory illness in a working population. Individuals with severe alpha-1-antitrypsin $(\alpha 1 \mathrm{AT})$ deficiency (phenotype Pi ZZ) are abnormally liable to develop emphysema, but it is uncertain whether those with partial $\alpha 1$ AT deficiency (phenotypes Pi MS and MZ) are similarly susceptible. This study was undertaken to determine the frequency of the various Pi phenotypes in a working population in Northern Ireland and to compare the performance of simple pulmonary function tests and prevalence of respiratory symptoms and chest illness between different phenotypes. The population sample consisted of 1995 working men and women aged between 35 and 70 years. The MRC Questionnaire (1966) was used to assess respiratory symptoms, a forced expiratory spirogram was recorded, and a blood sample was analysed for $\alpha 1 \mathrm{AT}$ phenotype by acid starch gel electrophoresis and antigen-antibody crossed electrophoresis in every case.

The percentage frequencies of the $\alpha 1 \mathrm{AT}$ phenotypes were: Pi MM 86.5; MS 7.97; MZ 3.86; IM 0.6; FM 0.4; SZ 0.25; M- 0.15; SS 0.1; Z- 0.05; MP 0.05; FS 0.05. Respiratory symptoms and a history of previous chest illness occurred with similar frequency among the Pi M, MS, and MZ phenotypes, and a comparison of the regression coefficients for $\mathrm{FEV}_{1}, \mathrm{FVC}$, and MMF on age for each phenotype group showed no significant differences between them overall, or when subdivided according to smoking habits or dust exposure. These findings provide no evidence that individuals of phenotype Pi MS or MZ are more than usually liable to develop chronic airways obstruction.
\end{abstract}

Individuals with severe deficiency of the serum protein alpha-1-antitrypsin ( $\alpha 1 \mathrm{AT}$ ) were observed by Eriksson (1964) to have an increased liability to develop panacinar emphysema of early onset. Further studies have shown that in an unselected population there exists a number of $\alpha 1 \mathrm{AT}$ 'variants' or phenotypes which are determined by a system of multiple autosomal codominant alleles known as the $\mathrm{Pi}$ or protease inhibitor system (Fagerhol and Laurell, 1970). More than 30 phenotypes have been described (Cook, 1974), the allele products being named alphabetically accord- ing to their electrophoretic mobility in acid starch gel. Population studies have shown that the frequencies of different $\alpha 1 \mathrm{AT}$ phenotypes in Scandinavian, American, and European populations are fairly consistent, the PI $\mathbf{M}$ phenotype occurring in about $88-90 \%, \mathrm{Pi} \mathrm{MS}$ in $4-8 \%, \mathrm{Pi} \mathrm{MZ}$ in $2-4 \%$, and the numerous remaining phenotypes together making up about $3 \%$ or less of normal populations (Fagerhol, 1967; Webb et al., 1973; Blundell et al., 1975b). Estimates based on large population studies have suggested that the frequency of the emphysema-associated $\mathrm{Pi} \mathrm{ZZ}$ 
phenotype in Sweden would be 1 in 1750 of the population (Eriksson, 1965) compared with 1 in 3460 in England and Wales (Cook, 1974).

It has been shown that $\alpha 1 \mathrm{AT}$ phenotype is an important factor in determining the concentration of $\alpha 1 \mathrm{AT}$ in the serum, individuals with the $\mathrm{Pi} \mathrm{ZZ}$ phenotype having a mean serum concentration only $15 \%$ of the average level found in $\mathrm{Pi}$ MM subjects (Ganrot, Laurell, and Eriksson, 1967) while the majority of other phenotypes show intermediate levels, the Pi MS and Pi MZ phenotypes having mean serum concentrations of 83 and $61 \%$ respectively of the mean $\mathrm{Pi} \mathrm{MM}$ level (Fagerhol, 1969). It would be of considerable epidemiological interest to know whether individuals of Pi MS and Pi MZ phenotype, who together make up at least $10 \%$ of the populations described above, are more liable to develop emphysema than the majority with the phenotype $\mathrm{Pi}$ M. The objective of the present investigation is to compare pulmonary function and the prevalence of respiratory symptoms and chest illnesses between the Pi M, MS, and MZ phenotype groups in a large population.

\section{MATERIAL AND METHODS}

The subjects studied were 1995 working people in Northern Ireland, drawn from hospital workers, civil servants, factory and building site workers, and blood donors from many walks of life who were leading normal active working lives. They were 'self-selected' in the sense that they were informed of the nature and objectives of the study and then invited to participate. Only those over 35 years of age were approached because it was thought that below this age level symptoms or signs of incipient chronic airways obstruction might not yet have begun to show themselves. At interview the MRC questionnaire on respiratory symptoms (Medical Research Council, 1966) was completed and subsequently coded according to the definitions outlined in Appendix 1. ${ }^{1}$ Each subject recorded five forced expiratory spirograms using a Vitalograph dry spirometer, the last three being averaged for one-second forced expired volume $\left(F E V_{1}\right)$ and forced vital capacity (FVC) while maximum mid-expiratory flow rate (MMF) was measured from the best of the five tracings. Gas volumes were corrected to BTPS.

A $10 \mathrm{ml}$ venous blood sample was obtained from each subject, and the serum was analysed for $\alpha 1 \mathrm{AT}$ level by an automated immunoprecipitin technique using a Technicon AutoAnalyzer. Ali-

\footnotetext{
${ }^{1}$ The two appendices are available on application to Dr. R. B. Cole
}

quots of pooled clear sera from 160 healthy adults of Pi $\mathrm{M}$ phenotype were deep frozen and served as a reference standard to which a value of $100 \%$ was assigned. Alpha-1-antitrypsin phenotyping was carried out by acid starch gel electrophoresis using a modification of the method of Fagerhol (1968) and confirmed in every case by antigen-antibody crossed electrophoresis by a modification of the methods described by Ganrot (1972). Further details of the electrophoretic methods used in this study are described elsewhere (Blundell et al., 1975b).

Individuals heterozygous for the $P i$ - gene were identified by family studies which were completed only after the results of the survey had been analysed. Subjects of Pi M- phenotype have been included in the analysis with the Pi MM group which is therefore designated $\mathrm{Pi} \mathrm{M}$.

STATISTICAL ANALYSES All data were transferred to ICL 80 column punch cards. The data processing and the regression analyses described below were carried out on the Queen's University ICL 1906S and 1907 computers using ICL packages XDSD and XDS3. The conventional level of significance, $P<0.05$, has been used throughout.

Since the prevalences of the symptoms and chest illnesses considered (Appendix 1) may be influenced by age, area of residence (as a crude measure of atmospheric pollution), smoking habits, and exposure to dust during work, preliminary analyses ( $\chi^{2}$ tests) were carried out to determine whether the distribution of each of these factors, and of sex, height, and weight, differed significantly between the three phenotype groups; non-significance would justify the comparison of prevalences between phenotypes for all levels of the possible influencing factors combined. Because of the possibility of interactions between these factors a standardizing technique was applied, as described by Elwood et al. (1965).

Because one of the principal features of the severely deficient $\alpha 1 \mathrm{AT}$ phenotype $\mathrm{Pi} \mathrm{ZZ}$ is the onset of emphysema at a relatively early age (Eriksson, 1965) it seemed possible by analogy that a more rapid decline in pulmonary function with age might occur in the partially deficient $\mathrm{Pi}$ MS or Pi MZ phenotypes compared with the normal Pi M. In order to make this comparison the $\mathrm{FEV}_{1}, \mathrm{FVC}$, and MMF values were standardized to a common height and regression coefficients of these standardized values on age were then derived for each phenotype, males and females separately, and also for certain subgroups classified according to current smoking habits or to exposure to dust 
during work. For each sex, these regression coefficients were compared between phenotypes using a well-known technique (eg, Quenouille, 1952; Snedecor and Cochran, 1968). Where corresponding coefficients did not differ significantly between the phenotypes it was possible to compare mean levels of lung function, adjusted to a common age, between the phenotypes by covariance analysis, ie, a test of difference in positions of parallel regression lines.

\section{RESULTS}

Pi PHENOTYPES The distribution of the different phenotypes and the corresponding mean serum concentrations of $\alpha 1 \mathrm{AT}$ for each phenotype are shown in Table I.

T A B L E I

DISTRIBUTION OF PHENOTYPES AND SERUM aIAT LEVELS

\begin{tabular}{|c|c|c|c|}
\hline Phenotype & Number & $\begin{array}{l}\text { Percentage } \\
\text { Incidence }\end{array}$ & $\begin{array}{l}\text { Serum al AT Level } \\
\text { as per cent } \\
\text { Reference Standard } \\
\text { (mean } \pm 2 \text { SD) }\end{array}$ \\
\hline $\begin{array}{l}\text { MM } \\
\mathbf{M S} \\
\mathbf{M Z} \\
\mathbf{I M} \\
\mathbf{F M} \\
\mathbf{S Z} \\
\mathbf{M}- \\
\mathbf{S S} \\
\mathbf{Z}- \\
\mathbf{M P} \\
\mathbf{F S}\end{array}$ & $\begin{array}{r}1726 \\
159 \\
77 \\
12 \\
8 \\
5 \\
3 \\
2 \\
1 \\
1 \\
1\end{array}$ & $\begin{array}{r}86 \cdot 50 \\
7.97 \\
3.86 \\
0.60 \\
0.40 \\
0.25 \\
0.15 \\
0 \cdot 10 \\
0.05 \\
0.05 \\
0.05\end{array}$ & $\begin{array}{l}100(69-131) \\
81(58-104) \\
60(41-80) \\
83 \\
97 \\
39 \\
57 \\
71 \\
5 \\
68 \\
66\end{array}$ \\
\hline Total & 1995 & & \\
\hline
\end{tabular}

RESPIRATORY SYMPTOMS AND ILLNESSES Preliminary analyses showed that the three phenotype groups, Pi M, MS, and MZ, did not differ significantly with respect to distribution of age, area of residence or smoking habits, nor to distribution of sex, height or weight. Only for duration of exposure to dust did the three phenotype groups differ significantly $\left(\chi^{2}=17.91, \mathrm{df}=6,0.01>\mathrm{p}>\right.$ 0.001 ), the results suggesting that a larger proportion of the Pi MS and MZ groups had never been exposed compared with the Pi M group. Prevalence rates of respiratory symptoms (Table II) and frequency of previous chest illnesses (Table III) have therefore been tabulated according to the subjects' exposures to dust.

Tables IIa and b suggest that for all subjects, irrespective of exposure to dust, and for subjects not exposed to dust the prevalences of breathlessness and wheezing are greatest in the $\mathrm{Pi} \mathrm{MZ}$ group. However, no significant differences in prevalence between phenotypes were found for any of the four respiratory symptoms concerned. The small number of subjects exposed to dust, particularly in the Pi MS and MZ groups, prevented a formal comparison of the prevalences (Table IIc).

Table III shows the percentage number with a past history of bronchitis or emphysema for all subjects (Table IIIa), for subjects not exposed to dust (Table IIIb), and for subjects exposed to dust (Table IIIc). The percentage with previous bronchitis or emphysema was greatest in the Pi MZ group but the differences were not statistically significant. A greater proportion of Pi MZ subjects compared to $\mathrm{Pi} \mathbf{M}$ and $\mathrm{MS}$ subjects was found to have had a past history of pneumonia but again the phenotype differences were not significant. Furthermore, the percentage with a previous history of pleurisy did not differ significantly between the phenotypes.

The results of the standardization analysis confirmed that there were no significant differences between phenotype groups for either the respiratory symptoms of Table II or the chest illnesses of Table III.

PHYSIOLOGICAL VARIABLES Of the 1965 subjects of $\mathrm{Pi} \mathrm{M}, \mathrm{MS}$, or $\mathrm{MZ}$ phenotype included in this study, $54(2 \cdot 7 \%)$ were omitted from the analysis of respiratory function because of deficiencies in the data, due to omissions in the questionnaires, unsatisfactory performance of the forced expiration or initial uncertainty in phenotyping ( 7 cases).

The following regression equations were derived from data relating to 'ideal normals', ie, asymptomatic Pi M subjects who had no serious chest illness and had never smoked or been exposed to toxic dust during work:

Males $(\mathrm{N}=184)$

$\mathrm{FEV}_{1}=-3.9461+0.0458$ Height

$(r=0.4480)$

$\mathrm{FVC}=-6.9384+0.0686$ Height

$(r=0.5788)$

$\mathrm{MMF}=1 \cdot 2449+0 \cdot 0161$ Height

$(r=0.0898)$

Females $(\mathrm{N}=179)$

$\mathrm{FEV}_{1}=-4.5976+0.0455$ Height $\quad(\mathrm{r}=0.4682)$

$F V C=-6.3252+0.0600$ Height $\quad(r=0.5252)$

$\mathrm{MMF}=-3 \cdot 1523+0.0380$ Height $\quad(r=0.2636)$

Using the above equations, levels of $\mathrm{FEV}_{1}, \mathrm{FVC}$, and MMF of each of the 1224 males were corrected to a common height of $172 \mathrm{~cm}$, while those of the 687 females were corrected to a common height of $160 \mathrm{~cm}$. (The correlation coefficient for MMF in males was not significant, but for the sake of consistency these values also were corrected, even though in practice the correction was negligible because of the poor correlation.) The regression coefficients of these corrected values on age were then calculated for 
T A B L E I I

PERCENTAGE PREVALENCE OF RESPIRATORY SYMPTOMS ACCORDING TO PHENOTYPE

\begin{tabular}{|c|c|c|c|c|c|c|}
\hline \multirow[b]{2}{*}{ Symptom } & \multicolumn{3}{|c|}{ Phenotype } & \multirow[b]{2}{*}{$\chi^{2}$} & \multirow[b]{2}{*}{ df } & \multirow[b]{2}{*}{$\mathbf{P}$} \\
\hline & $\mathbf{M}$ & MS & $\mathbf{M Z}$ & & & \\
\hline $\begin{array}{l}\text { (a) All subjects } \\
\text { Cough } \\
\text { Phlegm } \\
\text { Breathlessness } \\
\text { Wheezing }\end{array}$ & $\begin{array}{c}(\mathrm{N}=1726) \\
11 \cdot 9 \\
12 \cdot 1 \\
3 \cdot 2 \\
7 \cdot 1\end{array}$ & $\begin{array}{c}(\mathrm{N}=158) \\
10 \cdot 1 \\
10 \cdot 1 \\
3 \cdot 8 \\
6 \cdot 3\end{array}$ & $\begin{array}{c}(\mathrm{N}=74) \\
9 \cdot 5 \\
9 \cdot 5 \\
5 \cdot 4 \\
10 \cdot 8\end{array}$ & $\begin{array}{l}0.79 \\
0.92 \\
1.11 \\
1.67\end{array}$ & $\begin{array}{l}2 \\
2 \\
2 \\
2\end{array}$ & $\begin{array}{l}0.50-0.70 \\
0.50-0.70 \\
0.50-0.70 \\
0.30-0.50\end{array}$ \\
\hline $\begin{array}{l}\text { (b) Subjects not exposed } \\
\text { to dust } \\
\text { Cough } \\
\text { Phlegm } \\
\text { Breathlessness } \\
\text { Wheezing }\end{array}$ & $\begin{array}{c}(\mathrm{N}=1371) \\
11 \cdot 0 \\
10 \cdot 5 \\
2 \cdot 5 \\
6 \cdot 3\end{array}$ & $\begin{array}{c}(\mathrm{N}=140) \\
10 \cdot 0 \\
10 \cdot 7 \\
4 \cdot 3 \\
5 \cdot 0\end{array}$ & $\begin{array}{c}(\mathrm{N}=69) \\
7 \cdot 3 \\
8 \cdot 7 \\
5 \cdot 8 \\
10 \cdot 1\end{array}$ & $\begin{array}{l}1 \cdot 06 \\
0.24 \\
3 \cdot 95 \\
2 \cdot 08\end{array}$ & $\begin{array}{l}2 \\
2 \\
2 \\
2\end{array}$ & $\begin{array}{l}0.50-0.70 \\
0.80-0.90 \\
0.10-0.20 \\
0.30-0.50\end{array}$ \\
\hline $\begin{array}{l}\text { (c) Subjects exposed } \\
\text { to dust } \\
\text { Cough } \\
\text { Phlegm } \\
\text { Breathlessness } \\
\text { Wheezing }\end{array}$ & $\begin{array}{c}(\mathrm{N}=355) \\
15 \cdot 2 \\
18 \cdot 0 \\
6 \cdot 2 \\
9 \cdot 9\end{array}$ & $\begin{array}{c}(\mathrm{N}=18) \\
11 \cdot 1 \\
5 \cdot 6 \\
1 \overline{6 \cdot 7}\end{array}$ & $\begin{array}{c}(\mathrm{N}=5) \\
40 \cdot 0 \\
20 \cdot 0 \\
\overline{20 \cdot 0}\end{array}$ & & & \\
\hline
\end{tabular}

T A B L E I I I

PERCENTAGE PREVALENCE OF PREVIOUS RESPIRATORY ILLNESS ACCORDING TO PHENOTYPE

\begin{tabular}{|c|c|c|c|c|c|c|}
\hline \multirow[b]{2}{*}{ Previous Illness } & \multicolumn{3}{|c|}{ Phenotype } & \multirow[b]{2}{*}{$x^{2}$} & \multirow[b]{2}{*}{ df } & \multirow[b]{2}{*}{$\mathbf{P}$} \\
\hline & $\mathbf{M}$ & MS & MZ & & & \\
\hline $\begin{array}{l}\text { (a) All subjects } \\
\text { Bronchitis/emphysema } \\
\text { Other chest illness } \\
\text { Pneumonia } \\
\text { Pleurisy }\end{array}$ & $\begin{array}{l}(\mathrm{N}=1726) \\
16 \cdot 4 \\
13 \cdot 6 \\
8 \cdot 1 \\
9 \cdot 2\end{array}$ & $\begin{array}{c}(\mathrm{N}=158) \\
15 \cdot 2 \\
9 \cdot 5 \\
8 \cdot 2 \\
5 \cdot 1\end{array}$ & 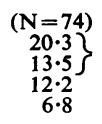 & $\begin{array}{l}3 \cdot 38 \\
1 \cdot 53 \\
3 \cdot 50\end{array}$ & $\begin{array}{l}4 \\
2 \\
2\end{array}$ & $\begin{array}{l}0 \cdot 30-0 \cdot 50 \\
0 \cdot 30-0.50 \\
0 \cdot 10-0 \cdot 20\end{array}$ \\
\hline $\begin{array}{l}\text { (b) Subjects not exposed } \\
\text { to dust } \\
\text { Bronchitis/emphysema } \\
\text { Other chest illness } \\
\text { Pneumonia } \\
\text { Pleurisy }\end{array}$ & $\begin{array}{c}(\mathrm{N}=1371) \\
15 \cdot 5 \\
13 \cdot 3 \\
8 \cdot 0 \\
8 \cdot 5\end{array}$ & $\begin{array}{c}(\mathrm{N}=140) \\
13 \cdot 8 \\
9 \cdot 3 \\
8 \cdot 6 \\
3 \cdot 6\end{array}$ & 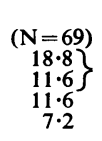 & $\begin{array}{l}3 \cdot 23 \\
1 \cdot 13 \\
4 \cdot 29\end{array}$ & $\begin{array}{l}4 \\
2 \\
2\end{array}$ & $\begin{array}{l}0 \cdot 50-0 \cdot 70 \\
0 \cdot 50-0 \cdot 70 \\
0 \cdot 10-0 \cdot 20\end{array}$ \\
\hline $\begin{array}{l}\text { (c) Subjects exposed to dust } \\
\text { Bronchitis/emphysema } \\
\text { Other chest illness } \\
\text { Pneumonia } \\
\text { Pleurisy }\end{array}$ & $\begin{array}{c}(\mathrm{N}=355) \\
20 \cdot 0 \\
14 \cdot 4 \\
8 \cdot 5 \\
11 \cdot 8\end{array}$ & $\begin{array}{c}(\mathrm{N}=18) \\
27 \cdot 8 \\
11 \cdot 1 \\
5 \cdot 6 \\
16 \cdot 7\end{array}$ & $\begin{array}{l}(\mathrm{N}=5) \\
40 \cdot 0 \\
40 \cdot 0 \\
20 \cdot 0 \\
-\end{array}$ & & & \\
\hline
\end{tabular}

(1) all males and all females separately (Table IV),

(2) males and females separately according to whether or not the subject was exposed to dust during work (Table Ia in Appendix 2), and

(3) males and females separately according to each subject's current smoking habits (Table Ib in Appendix 2).

Many of these coefficients were already based on small numbers of readings, and this prevented a further breakdown into subgroups defined according to sex, exposure to dust, and current smoking habits simultaneously.

The vast majority of coefficients were negative as expected, but comparison of the slopes between phenotypes (Table Va, and Tables $2 a$ and $3 a$ in
Appendix 2) revealed only one significant difference, namely, FVC on age in males exposed to dust which apeared to have arisen because of a positive coefficient found for Pi MS subjects. On the other hand, comparisons of the positions of the lines relating $\mathrm{FEV}_{1}, \mathrm{FVC}$, and MMF to age showed some significant differences (Table $\mathrm{Vb}$, and Tables $2 \mathrm{~b}$ and $3 \mathrm{~b}$ in Appendix 2). The mean values of $\mathrm{FEV}_{1}, \mathrm{FVC}$, and MMF adjusted to a common 6 age within each comparison indicate the differences in positions of the lines for the three phenotypes (Table VI, and Tables $4 \mathrm{a}$ and $\mathrm{b}$ in Appendix 2). For males, adjusted mean values of $F V_{1}$, FVC, and MMF in the Pi MS and MZ phenotypes tended to exceed the corresponding adjusted values of the $\mathbf{P i} \mathbf{M}$ groups, the differences being statistically significant in a number of instances 
T A B L E I V

REGRESSION COEFFICIENTS OF FEV ${ }_{1}$, FVC, AND MMF (ADJUSTED TO A COMMON HEIGHT) ON AGE

\begin{tabular}{c|c|c|ccc}
\hline Sex & Phenotype & N & FEV & FVC & MMF \\
\cline { 2 - 5 } Male & M & 1078 & $-0.0412 \pm 0.0022$ & $-0.0423 \pm 0.0023$ & $-0.0605 \pm 0.0042$ \\
& MS & 98 & $-0.0468 \pm 0.0068$ & $-0.0455 \pm 0.0075$ & $-0.0627 \pm 0.0141$ \\
Female & MZ & 48 & $-0.0372 \pm 0.0104$ & $-0.0343 \pm 0.0101$ & $-0.0575 \pm 0.0248$ \\
& MS & 609 & $-0.0323 \pm 0.0024$ & $-0.0345 \pm 0.0027$ & $-0.0384 \pm 0.0045$ \\
& MZ & 53 & $-0.0309 \pm 0.0088$ & $-0.0306 \pm 0.0098$ & $-0.0523 \pm 0.0173$ \\
& & 25 & $-0.0195 \pm 0.0119$ & $-0.0165 \pm 0.0124$ & $-0.0398 \pm 0.0270$
\end{tabular}

Further tables relating to the groups subdivided according to dust exposure and smoking habits are included in Appendix 2 (Tables 1a and 1b).

T A B L E V

COMPARISON OF THE SLOPES AND POSITIONS OF THE REGRESSION LINES OF FEV ${ }_{1}$, FVC, AND MMF ON AGE BETWEEN PHENOTYPES

\begin{tabular}{|c|c|c|c|c|c|c|c|c|c|c|c|c|}
\hline & \multicolumn{4}{|c|}{$\mathrm{FEV}_{1}$} & \multicolumn{4}{|c|}{ FVC } & \multicolumn{4}{|c|}{ MMF } \\
\hline & $\mathbf{F}$ & $n_{1}$ & $\mathrm{n}_{2}$ & $\mathbf{P}$ & $\mathbf{F}$ & $\mathrm{n}_{1}$ & $\mathrm{n}_{2}$ & $\mathbf{P}$ & $\mathbf{F}$ & $n_{1}$ & $\mathbf{n}_{2}$ & $\mathbf{P}$ \\
\hline $\begin{array}{l}\text { (a) Slopes of the } \\
\text { regression lines } \\
\text { All males } \\
\text { All females }\end{array}$ & $\begin{array}{l}0.44 \\
0.62\end{array}$ & 2 & $\begin{array}{r}1218 \\
681\end{array}$ & $\begin{array}{l}>0.20 \\
>0.20\end{array}$ & $\begin{array}{l}0.44 \\
1.06\end{array}$ & $\begin{array}{l}2 \\
2\end{array}$ & $\begin{array}{r}1218 \\
681\end{array}$ & $\begin{array}{l}>0.20 \\
>0.20\end{array}$ & $\begin{array}{l}0.03 \\
0.40\end{array}$ & $\begin{array}{l}2 \\
2\end{array}$ & $\begin{array}{r}1218 \\
681\end{array}$ & $\begin{array}{l}>0.20 \\
>0.20\end{array}$ \\
\hline $\begin{array}{l}\text { (b) Positions of the } \\
\text { regression lines } \\
\text { All males } \\
\text { All females }\end{array}$ & $\begin{array}{r}10.44 \\
0.03\end{array}$ & 2 & $\begin{array}{r}1220 \\
683\end{array}$ & $\begin{array}{l}<0.001 \\
>0.20\end{array}$ & $\begin{array}{l}6 \cdot 68 \\
0.25\end{array}$ & $\begin{array}{l}2 \\
2\end{array}$ & $\begin{array}{r}1220 \\
683\end{array}$ & $\begin{array}{l}<0.01 \\
>0.20\end{array}$ & $\begin{array}{l}6.98 \\
0.23\end{array}$ & $\begin{array}{l}2 \\
2\end{array}$ & $\begin{array}{r}1220 \\
683\end{array}$ & $\begin{array}{l}<0.001 \\
>0.20\end{array}$ \\
\hline
\end{tabular}

Further tables relating to the groups subdivided according to dust exposure and smoking habits are included in Appendix 2 (Tables 2 and 3).

T A B L E V I

AGE-ADJUSTED MEAN VALUES FOR FEV ${ }_{1}$, FVC, AND MMF ACCORDING TO PHENOTYPE

\begin{tabular}{|c|c|c|c|c|c|c|c|c|c|}
\hline & \multicolumn{3}{|c|}{$\mathrm{FEV}_{1}$ (litres) } & \multicolumn{3}{|c|}{ FVC (litres) } & \multicolumn{3}{|c|}{ MMF $\left(1 \mathrm{sec}^{-1}\right)$} \\
\hline & $\mathbf{M}$ & MS & MZ & $\mathbf{M}$ & MS & $\mathbf{M Z}$ & $\mathbf{M}$ & MS & MZ \\
\hline $\begin{array}{l}\text { All males } \\
\text { All females }\end{array}$ & $\begin{array}{l}3.58 \\
2.53\end{array}$ & $\begin{array}{l}3 \cdot 86 \\
2 \cdot 51\end{array}$ & $\begin{array}{l}3 \cdot 71 \\
2 \cdot 54\end{array}$ & $\begin{array}{l}4 \cdot 57 \\
3 \cdot 16\end{array}$ & $\begin{array}{l}4 \cdot 79 \\
3 \cdot 11\end{array}$ & $\begin{array}{l}4 \cdot 73 \\
3 \cdot 18\end{array}$ & $\begin{array}{l}3.44 \\
2 \cdot 66\end{array}$ & $\begin{array}{l}3 \cdot 86 \\
2 \cdot 72\end{array}$ & $\begin{array}{l}3 \cdot 70 \\
2 \cdot 75\end{array}$ \\
\hline
\end{tabular}

Further tables relating to the groups subdivided according to dust exposure and smoking habits are included in Appendix 2 (Tables 4a and b).

(see $F$ values of Table $\mathrm{Vb}$, and Tables $2 b$ and $3 b$ in Appendix 2). A similar trend was not readily apparent in the data for females.

\section{DISCUSSION}

The results of this study show that the distribution of $\mathrm{Pi}$ phenotypes in the working population of Northern Ireland, and the serum level of $\alpha 1 \mathrm{AT}$ for the different phenotypes, are similar to the results of population surveys in Norway (Fagerhol, 1967) and North America (Webb et al., 1973). They are also consistent with data for the rest of Britain described by Cook (1975), the slightly greater frequency of the $\mathrm{Pi} \mathrm{MZ}$ phenotypes in the Northern Ireland population (3.6\% compared with Cook's $1.5 \%$ ) being possibly attributable to the greater precision of antigen-antibody crossed electrophoresis used as a means of identifying this phenotype in the present study. Calculations of gene frequency from this population sample indicate that one individual of PiZZ phenotype would be expected in every 2312 people living in
Northern Ireland. Absence of an $\alpha 1$ AT gene (socalled $\mathrm{Pi}^{-}$) was suspected in four individuals because of unexpectedly low serum levels of $\alpha 1 \mathrm{AT}$, and confirmed by family studies (Blundell et al., 1975a).

The numbers of individuals identified as Pi MS and $\mathrm{MZ}$ were large enough to allow some statistical comparisons to be made between these phenotype groups and the major $\mathrm{Pi} M$ group with respect to respiratory symptoms and illness and to the performance of simple tests of pulmonary function. Nevertheless the numbers of individuals were small in some of the subgroups relating to current smoking habits and exposure to dust during work, particularly with regard to the $\mathbf{P i}$ MZ phenotype, so that the interpretation of significant or non-significant differences between particular subgroups must be tentative.

The apparent similarity between the Pi M, MS, and $\mathrm{MZ}$ phenotypes in the prevalence of respiratory symptoms or of previous chest illness may simply have been attributable to the greater dust 
exposure of the Pi $\mathbf{M}$ group: had dust exposure been similar in all three groups, a significant advantage to the $\mathrm{Pi} M$ group might have been observed. Although this interpretation cannot be dismissed it is not borne out by the analysis of physiological tests in the present study, which showed that where a significant difference in $\mathrm{FEV}_{1}$, FVC or MMF was demonstrable between any of the three phenotype groups when classified according to dust exposure the performance of the PiM phenotype group appeared to be generally worse than that of the other two phenotypes. In a comparable population survey, Webb et al. (1973) found no evidence that a history of pulmonary disease or respiratory symptoms was more common among MS or MZ subjects than MM subjects, and some further support for our findings comes from the large community study of Morse et al. (1975), who were unable to show any correlation between respiratory symptoms, chest illness or pulmonary function and variations in serum trypsin inhibitory capacity which must in some measure have reflected the different $\alpha 1 \mathrm{AT}$ phenotypes in their population. However, quantitative methods for measuring $\alpha 1 \mathrm{AT}$ in the serum, such as trypsin inhibitory capacity or immunodiffusion, have proved to be misleading as a means of distinguishing between different phenotypes (Talamo et al., 1972; Kanner et al., 1973), and it is difficult to assess the significance of the numerous studies which have used quantitative methods as the basis for investigating the relationship between $\alpha 1 \mathrm{AT}$ 'heterozygotes' and pulmonary disease (Lieberman, Mittman, and Schneider, 1969; Richardson et al., 1969; Welch et al., 1969, Mittman et al., 1971; Resnick, Lapp, and Morgan, 1971).

A more rigorous assessment can be made of those investigations in which the phenotypes of the individuals under scrutiny were reliably established either by antigen-antibody crossed electrophoresis or, in the case of $\mathrm{Pi} \mathbf{M Z}$ subjects, as 'obligatory heterozygotes' because of their firstdegree relationship to $\mathrm{Pi} \mathrm{Z}$ individuals. In three fairly small groups of obligatory heterozygotes, totalling 95 individuals in all, there was said to be no increased prevalence of pulmonary disease (Eriksson 1965; Guenter et al., 1971) or evidence of severe emphysema (Hutchison, 1973). Studying a series of 196 patients attending chest clinics for 'chronic' obstructive lung disease', Fagerhol and Hauge (1969) found an unexpectedly high number of Pi SS, SZ, and ZZ phenotypes but not of $\mathrm{Pi} \mathrm{MZ}$, while Talamo et al. (1972) similarly found no excess of Pi MZ individuals in a group of 99 such patients. In contrast, Mittman and
Lieberman (1972) found $11.3 \%$ of $\mathrm{Pi} \mathrm{MZ}$ and $4 \%$ of $\mathrm{Pi} \mathrm{ZZ}$ individuals in 124 consecutive chest clinic cases, and Kueppers and Dönhardt (1974) identified $12 \mathrm{Pi} \mathrm{MZ}$ cases among 166 patients with chronic obstructive lung disease and only one among 200 normal blood donors, a difference which was significant. More recently, Barnett, Gottovi, and Johnson (1975) found a significant excess of individuals of $\mathrm{Pi} \mathrm{MZ}$ and $\mathrm{ZZ}$ phenotypes among 107 chest clinic patients with 'chronic obstructive lung disease' when compared with 97 control subjects. It seems likely that differences in the criteria for selection of patients must play some part in explaining these divergent results.

Turning to physiological tests of pulmonary function, some inconsistencies are apparent between the results of different investigators. The only study which, like our own, has compared tests of pulmonary function between large unselected but clearly identified phenotype groups (Webb et al., 1973) similarly showed no significant difference between Pi M, MS, and MZ phenotypes using the simple measurements of function which can be derived from a forced expiratory spirogram. On the other hand, several investigations using a variety of more or less sophisticated tests to compare a carefully identified small group of $\mathrm{Pi} \mathbf{M Z}$ individuals with a matched group of $\mathrm{Pi} \mathbf{M}$ have described significant differences of function between these phenotypes. Ostrow and Cherniack (1972) compared 10 obligatory heterozygotes (Pi MZ) with 24 normal subjects well matched for age, sex, height, and smoking history but with an excess of symptomatic patients among the heterozygote group. They found no difference between the groups in subjects under 30 years of age, but in heterozygotes over 30 they found reduction in maximal expiratory flows and static elastic lung recoil, and some evidence of frequency dependence of compliance. Using routine tests of pulmonary function, Hall et al. (1973) were unable to distinguish $\mathbf{P i}$ MS or MZ individuals from matched $\mathrm{Pi} \mathbf{M}$ controls but did show a slight deficit in measurements of total pulmonary resistance and of maximal expiratory flow among nonsmoking Pi MZ subjects, although no difference was apparent among comparable groups of smokers of different phenotypes. Their results suggested that impairment of function was due more to smoking than to variation in $\alpha 1 \mathrm{AT}$ phenotype. Cooper et al. (1974) carried out a wide range of pulmonary function tests on 54 adults of Pi MZ phenotype and comparable studies on 69 matched Pi $M$ subjects, finding that arterial oxygen tension, static elastic recoil of the lung, maxi- 
mal expiratory flow at $25 \%$ of vital capacity, and possibly closing capacity were lower in the $\mathrm{Pi}$ $\mathrm{MZ}$ than in the Pi M group, and that these differences tended to be greater in smokers than in non-smokers. In our own laboratory, on the other hand, closing volume and closing capacity measurements on 54 normal individuals of Pi MZ phenotype have been compared with the results obtained in 207 normal subjects of Pi $\mathbf{M}$ without revealing any significant difference between the two phenotypes (Dr. B. Bradley, personal communication). There are, in addition, several further studies comparing various aspects of pulmonary function between different phenotypes identified by quantitative measurements only (Richardson et al., 1969; Mittman et al., 1971; Stevens et al., 1971) but the significance of the results is difficult to assess because of the inherent uncertainty of this method of phenotyping.

It seems likely that some of the divergencies between the results obtained by different investigators can be attributed to variations in the criteria used for selecting groups of patients with pulmonary disease, and to the difficulty of accurately 'matching' small groups of normal subjects of different $\alpha 1 \mathrm{AT}$ phenotypes without unintentional bias. The simple tests of pulmonary function, such as the forced expiratory spirogram and closing volume, which lend themselves most readily to large-scale surveys, have not revealed a significant physiological difference between Pi M, MS, and MZ phenotypes, while the slight hint derived from some of the more sophisticated investigations that individuals of $\mathrm{Pi} \mathrm{MZ}$ phenotype are at a disadvantage in terms of pulmonary function cannot be regarded as conclusive.

Although partial $\alpha 1 \mathrm{AT}$ deficiency alone may have too slight a detrimental effect on the lung to be easily measured, it has been suggested that individuals of $\mathrm{Pi} \mathrm{MZ}$ phenotype, and possibly of other phenotypes characterized by low $\alpha 1 \mathrm{AT}$ levels, may be more than usually susceptible to the harmful effects of inhaled materials such as cigarette smoke or dust (Mittman et al., 1971). The results of the present study give no support to this hypothesis, for no significant difference in the slopes of the regression lines relating the tests of pulmonary function to age was observed between similar subgroups of $\mathbf{P i} \mathbf{M}, \mathbf{M S}$ or $\mathbf{M Z}$ phenotypes when classified according to current smoking habits, or according to whether or not they had been exposed to dust during work. Indeed, the analysis of covariance comparing the mean values for FEV,$F V C$, and MMF when adjusted for age appears to indicate that in certain male subgroups the Pi MS and MZ phenotypes performed better than the corresponding Pi M subgroup, a finding which might be attributable in some instances to the rather small size of the subgroups. The limited extent of this survey did not permit an analysis of possible interactions between smoking habits and dust exposure in the comparisons of lung function between the three phenotype groups.

The conclusions from this investigation are also limited by the initial selection of a working population aged 35 years or more. Although this age group was chosen to ensure a reasonable proportion of individuals with clinical or functional evidence of pulmonary disease in the population studied, the effect of this selection on the subsequent analysis might have been to minimize a decline in pulmonary function with age and to have concealed a real difference between the phenotype groups which might have been apparent only before the age of 35 . Had such a disadvantage affected the Pi MS or MZ phenotypes rather than the Pi M group, however, one would have expected the analysis of covariance to have revealed a significant reduction in the mean values of $\mathrm{FEV}_{1}, \mathrm{FVC}$, and MMF in the Pi MS and MZ phenotypes relative to $\mathrm{Pi} \mathrm{M}$; in fact, the opposite was the case.

The fact that the population studied consisted only of working people indicates that invalids, hospital patients, and the unemployed were excluded, and further implies that if individuals of Pi MS or MZ phenotype are highly concentrated among such groups the results of a truly random population study might differ from the results of the present investigation. The evidence for and against an excessive preponderance of $\mathrm{Pi} \mathbf{M Z}$ subjects among chest clinic patients has been reviewed above, and it does not suggest that the distribution of phenotypes would be unduly biased by the exclusion of such patients from the population studied.

A population sample obtained by inviting the cooperation of individuals is subject to the criticism that those with symptoms or a family history of illness may avoid participation and so affect the validity of the sample. The observed prevalence of respiratory symptoms and of previous chest illness in the present study is consistent with other reports of the prevalence of chronic airways obstruction in Britain (eg, College of General Practitioners, 1961) and does not suggest that the sample studied differed in this respect from the general population.

Within these limitations we have found no evidence that individuals of Pi MS or MZ phenotype 
are more liable to show clinical or functional evidence of chronic airways obstruction than the bulk of the population of phenotype Pi M, and conclude that large-scale screening surveys to identify those who are unduly susceptible to pulmonary emphysema on the basis of their $\alpha 1 \mathrm{AT}$ phenotype would be of limited value since only the $\mathrm{Pi} \mathrm{Z}$ phenotype, which occurs once in approximately 2300 individuals, has been shown unequivocally to be at special risk.

We gratefully acknowledge the cooperation of the many members of the public who took part in this study, and the help given us by Colonel T. E. Field and the staff of the Northern Ireland Blocd Transfusion Service. Our warmest thanks are due to Miss Astrid Frazer and Miss Pat Thompson for their help with the biochemical estimations, and to Miss Diane Stirling for the secretarial work.

This study was carried out with the help of research grants from the Northern Ireland Hospitals Authority and the Eastern Health and Social Services Board.

\section{REFERENCES}

Barnett, T. B., Gottovi, D., and Johnson, A. M. (1975). Protease inhibitors in chronic obstructive pulmonary disease. American Review of Respiratory Disease, 111, 587.

Blundell, G., Cole, R. B., and Nevin, N. C. (1975a). The alpha-1-antitrypsin null gene frequency. In Protides of the Biological Fluids: Proceedings of the Twenty-third Colloquium, Brugge 1975, edited by $\mathrm{H}$. Peeters. Pergamon, Oxford. (In press).

—, Frazer, A., Cole, R. B., and Nevin, N. C. (1975b). Alpha-1-antitrypsin phenotypes in Northern Ireland. Annals of Human Genetics, 38, 289.

College of General Practitioners (1961). Chronic bronchitis in Great Britain. British Medical Journal, 2, 973.

Cook, P. J. L. (1974). Genetic aspects of the Pi system. Postgraduate Medical Journal, 50, 362.

(1975) The genetics of alpha-1-antitrypsin: a family study in England and Scotland. Annals of Human Genetics, 38, 275.

Cooper, D. M., Hoeppner, V., Cox, D., Zamel, N., Bryan, A. C., and Levison, H. (1974). Lung function in alpha-1-antitrypsin heterozygotes (Pi type MZ). American Review of Respiratory Disease, 110, 708.

Elwood, P. C., Pemberton, J., Merrett, J. D., Carey, G. C. R., and McAulay, I. R. (1965). Byssinosis and other respiratory symptoms in flax workers in Northern Ireland. British Journal of Industrial Medicine, 22, 27.

Eriksson, S. (1964). Pulmonary emphysema and alpha1-antitrypsin deficiency. Acta Medica Scandinavica, 175, 197.

(1965). Studies in alpha-1-antitrypsin deficiency. Acta Medica Scandinavica, Supplement 432.
Fagerhol, M. K. (1967). Serum Pi types in Norwegians. Acta Pathologica et Microbiologica Scandinavica, 70, 421.

(1968). The Pi system: genetic variants of serum alpha-1-antitrypsin. Series Haematologica, 1, 153. (1969). Quantitative studies on the inherited variants of serum alpha-1-antitrypsin. Scandinavian Journal of Clinical and Laboratory Investigation, 23, 97.

and Hauge, H. E. (1969). Serum Pi types in patients with pulmonary diseases. Acta Allergologica, 24, 107.

_ and Laurell, C-B. (1970). The Pi system-inherited variants of serum alpha-1-antitrypsin. Progress in Medical Genetics, 7, 96.

Ganrot, P. O. (1972). Crossed immunoelectrophoresis. Scandinavian Journal of Clinical and Laboratory Investigation, Supplement 124, 39.

- Laurell, C-B., and Eriksson, S. (1967). Obstructive lung disease and trypsin inhibitors in alpha-1antitrypsin deficiency. Scandinavian Journal of Clinical and Laboratory Investigation, 19, 205.

Guenter, C. A., Welch, M. H., Ferguson, S., Henderson, L., and Hammarsten, J. F. (1971). Alpha-1antitrypsin deficiency: heterozygosity, intermediate levels, and pulmonary disease. Chest, 59(5), Supplement, 16S.

Hall, W., Hyde, R., Schwartz, R., Webb, D. and Schoenewald, M. (1973). Quantification of small airway disease in heterozygotes for serum alpha1-antitrypsin deficiency. Clinical Reasearch, 21, 661.

Hutchison, D. C. S. (1973). Alpha-1-antitrypsin deficiency and pulmonary emphysema: the role of proteolytic enzymes and their inhibitors. British Journal of Diseases of the Chest, 67, 171.

Kanner, R. E., Klauber, M. R., Watanabe, S., Renzetti, A. D. Jr., and Bigler A. (1973). Pathologic patterns of chronic obstructive pulmonary disease in patients with normal and deficient levels of alpha-1-antitrypsin. American Journal of Medicine, 54, 706.

Kueppers, F. and Dönhardt, A. (1974). Obstructive lung disease in heterozygotes for alpha-1-antitrypsin deficiency. Annals of Internal Medicine, 80, 209.

Lieberman, J. (1969). Heterozygous and homozygous alpha-1-antitrypsin deficiency in patients with pulmonary emphysema. New England Journal of Medicine, 281, 279.

- Mittman, C., and Schneider, A. S. (1969). Screening for homozygous and heterozygous alpha-1-antitrypsin deficiency. Journal of the American Medical Association, 210, 2055.

Medical Research Council (1966). A questionnaire on respiratory symptoms approved by the MRC Committee on Research into Chronic Bronchitis.

Mittman, C. and Lieberman, J. (1972). Protease inhibitor phenotypes in patients with chronic lung disease. Clinical Research, $20,242$.

, - - Marasso, F., and Miranda, A. (1971). Smoking and chronic obstructive lung disease in alpha-1-antitrypsin deficiency. Chest, 60, 214. 
Morse, J. O., Lebowitz, M. D., Knudson, R. J., and Burrows, B. (1975). A community study of the relation of alpha-1-antitrypsin levels to obstructive lung diseases. New England Journal of Medicine, 292, 278.

Ostrow, D. N. and Cherniack, R. M. (1972). The mechanical properties of the lungs in intermediate deficiency of alpha-1-antitrypsin. American Review of Respiratory Disease, 106, 377.

Quenouille, M. H. (1952). Associated Measurements. Butterworth, London.

Resnick, H., Lapp, N. L., and Morgan, W. K. C. (1971). Serum trypsin inhibitor concentrations in coal miners with respiratory symptoms. Journal of the American Medical Association, 215, 1101.

Richardson, R. H., Guenter, C. A., Welch, M. H., Hyde, R. M., and Hammarsten, J. F. (1969). The pattern of inheritance of alpha-1-antitrypsin deficiency and associated pulmonary disease. American Review of Respiratory Disease, 100, 619.

Snedecor, G. W. and Cochran, W. G. (1968). Statistical Methods, 6th edition. Iowa State University Press, Iowa.
Stevens, P. M., Hnilica, V. S., Johnson, P. C., and Bell, R. L. (1971). Pathophysiology of hereditary emphysema. Annals of Internal Medicine, 74, 672.

Talamo, R. C., Langley, C. E., Levine, B. W., and Kazemi, H. (1972). Genetic vs. quantitative analysis of serum alpha-1-antitrypsin. New England Journal of Medicine, 287, 1067.

Webb, D. R., Hyde, R. W., Schwartz, R. H., Hall, W. J., Condemi J. J., and Townes, P. L. (1973). Serum alpha-1-antitrypsin variants: prevalence and clinical spirometry. American Review of Respiratory Disease, 108, 918.

Welch, M. H., Reinecke, M. E., Hammarsten, J. F., and Guenter, C. A. (1969). Antitrypsin deficiency in pulmonary disease: the significance of intermediate levels. Annals of Internal Medicine, 71, 533.

Requests for reprints or ccpies of the appendices to: Dr. R. B. Cole, Chest Radiology Centre, Central Outpatient Department, North Staffordshire Hospital Centre, Hartshill, Stoke-on-Trent, Staffordshire. 